\title{
Immunity to rubella in women of childbearing age in the United Kingdom
}

\author{
Norman D Noah, Sarah E Fowle
}

\begin{abstract}
In the first three years of a surveillance scheme for susceptibility to rubella in women aged 15-44 the results of over 1.3 million serological tests were collected by 80 laboratories throughout the United Kingdom. Seventy eight per cent of the results, or an average of 340000 a year, were from pregnant women, so that just under half of all pregnant women in the United Kingdom were reported on. Eighteen per cent of results were from women tested before vaccination and the remainder were from diagnostic and other tests. Pregnant women showed an overall downward trend in susceptibility to rubella (from $4.2 \%$ at the beginning of 1984 to $3.0 \%$ at the end of 1986), and a similar decline was seen in the two other categories. Regional data showed a significant negative correlation between the proportion of pregnant women aged 15-19 who were susceptible to the virus and rate of uptake of vaccine in 14 year old schoolgirls. Women aged 25-29 were least susceptible.

This form of laboratory surveillance is feasible and representative; it should be continued to monitor the effect of introducing the measles, mumps, and rubella vaccine.
\end{abstract}

\section{Introduction}

This study of susceptibility to rubella in women of childbearing age began in January 1984 and was motivated by the need to monitor such susceptibility systematically, especially as the Department of Health and Social Security had just begun a campaign to increase rates of immunisation against rubella in this population and in schoolgirls. National surveillance of congenital rubella is affected by problems of late detection and presentation of cases. Serological surveys have previously been conducted on selected populations, such as blood donors and university students, ${ }^{\prime}$ or local communities, such as general practices. $^{2-5}$ We present a summary of the results for the first three years of national surveillance of immunity to rubella. This report complements a more intensive study in eight public health laboratories that covered a smaller population. ${ }^{67}$ The words susceptibility and immunity are used in this paper to represent absence and presence of antibody to rubella, respectively, although these are not necessarily accurate measures of susceptibility and immunity.

\section{Methods}

All NHS laboratories (including public health laboratories) with a serological service for rubella were invited to contribute to a surveillance of immunity to rubella in women of childbearing age. Eighty laboratories responded (72 in England, five in Scotland, two in Wales, and one in Northern Ireland). These included two blood transfusion laboratories that performed a rubella serological service for their regions. All regional health authorities in England were represented.

Six months after the start of the study (January 1984) most of the laboratories had begun reporting. The number of reports settled to $115000-123000$ a quarter. Testing for antibodies to rubella was performed routinely in all pregnant women, even those already known to be seropositive. Of the 1318398 tests performed during the three years, $1031115(78 \cdot 2 \%)$ were on pregnant women (table I), giving an average of 343705 a year, which is equivalent to $45 \%$ of all pregnant women in the United Kingdom (46\% (287 187) in England, 28\% (10395) in Wales, 37\% (24648) in Scotland, and 65\% (18075) in Northern Ireland). Tests on women before vaccination

TABLE I-Number (percentage) of women tested for antibodies to rubella, 1984-6

\begin{tabular}{|c|c|c|c|c|}
\hline & Pregnant women & $\begin{array}{c}\text { Women tested } \\
\text { before } \\
\text { vaccination }\end{array}$ & $\begin{array}{l}\text { Women tested } \\
\text { for other reasons }\end{array}$ & Total \\
\hline 198 & $290152(77$. & 72060 & & 374 \\
\hline 1 & $367826(78$ & 83076 ( & 166 & 467527 \\
\hline 1986 & $373137(78 \cdot 3)$ & $82832(17 \cdot 4)$ & $20672(4 \cdot 3)$ & 476641 \\
\hline otal & $1031115(78 \cdot 2)$ & $237974(18 \cdot 1)$ & $49309(3 \cdot 7)$ & 13183 \\
\hline
\end{tabular}

accounted for $18 \%$ (237974) of the reported results, and the remaining $4 \%$ (49309) were diagnostic and other tests.

The method used for testing was known for 67 of the 80 laboratories. Fifty two used single radial haemolysis for primary routine screening (with $\geqslant 15 \mathrm{IU}$ as positive, $<15 \mathrm{IU}$ as equivocal, and no zone as negative), nine used enzyme linked immunosorbent assay (ELISA), three used haemagglutination inhibition, and three used latex agglutination. Haemagglutination inhibition, ELISA, and latex agglutination were used to confirm negative and equivocal results and to test pregnant women who had been in contact with rubella.

Results

TRENDS IN SUSCEPTIBILITY

Susceptibility to rubella decreased overall from 1984 to 1986 (fig 1). The decrease was greatest in women tested before vaccination, from $7 \cdot 7 \%(810 / 10501)$ in the first quarter of 1984 to $4 \cdot 4 \%(945 / 21589)$ in the last quarter of 1986 . The pregnant women showed a 
smaller decrease, from $4 \cdot 2 \%(1887 / 44420)$ to $3 \cdot 0 \%$ (2890/96 532) but had a lower overall susceptibility to rubella. Trends for both groups were broadly similar, the greatest decrease occurring during the first to third quarters of 1984 and the second to fourth quarters of 1986. The trend for the group tested for other reasons was less evident, although overall susceptibility decreased substantially from the second to fourth quarters of 1986.

\section{GEOGRAPHICAL DISTRIBUTION OF SUSCEPTIBILITY}

Susceptibility to rubella in pregnant women over the three years was lowest in Scotland and Northern Ireland (table II) and highest in England. The Northern region had the lowest average susceptibility rate in England (2.3\%), but this was higher than the rate in Scotland or Northern Ireland $(2 \cdot 0 \%)$. Susceptibility in the regions in England ranged from $2 \cdot 3 \%$ to $5 \cdot 8 \%$ (1533-2568 susceptible women), was generally in the range $3 \cdot 0-5 \cdot 0 \%$, and was generally higher in regions with mainly urban populations.

Rates for susceptibility were based on an average of 13000-40 000 tests a year in most regions, although the South Western and Mersey regions provided results on fewer than 8000 tests and the West Midlands on almost 90000 tests. Rates declined in most regions over the three years but increased slightly in West Midlands region. In North West Thames region the trends over time were inconsistent and difficult to interpret,

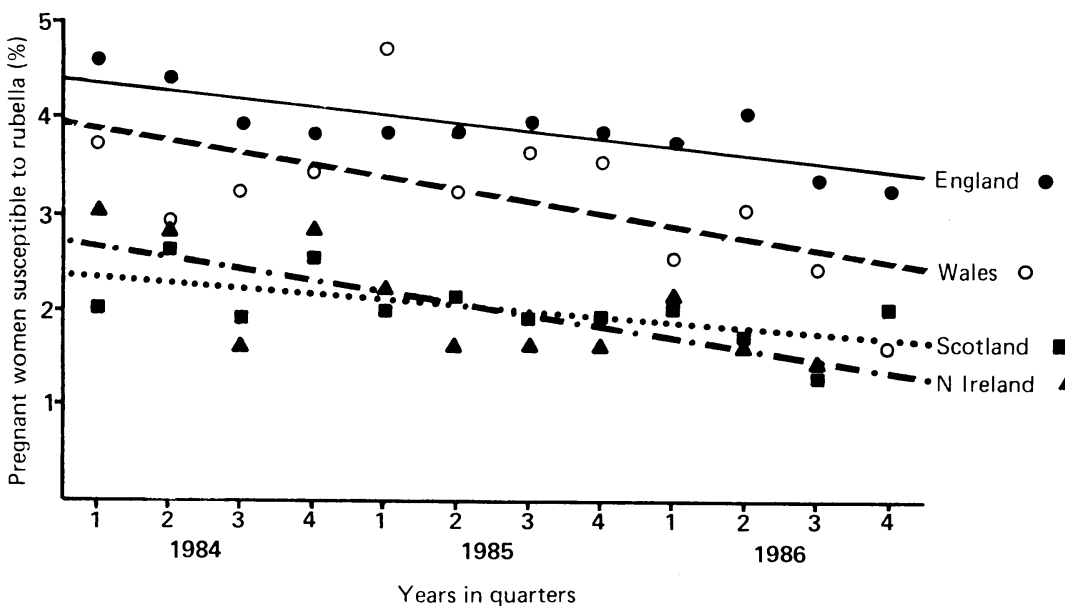

FIG 2-Regression lines for trends in susceptibility to rubella in pregnant women, 1984-6, in England, Wales, Scotland, and Northern Ireland

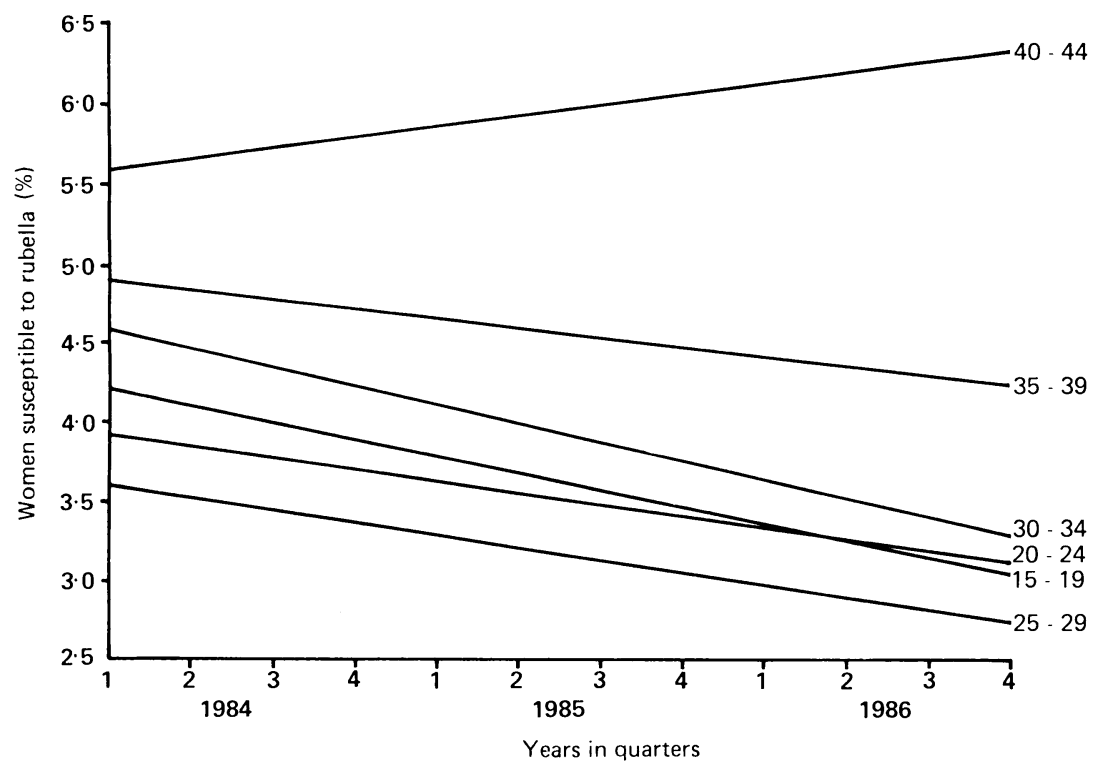

FIG 3-Lines of best fit for pregnant women susceptible to rubella by age group, 1984-6
TABLE II-Regional distribution of susceptibility to rubella in pregnant women, 1984-6

\begin{tabular}{lrrr}
\hline $\begin{array}{l}\text { Regional health } \\
\text { authority }\end{array}$ & No tested & No $(\%)$ susceptible & $\begin{array}{c}\text { Mean No of } \\
\text { tests/year }\end{array}$ \\
\hline Northern & 67236 & $1533(2 \cdot 3)$ & 25682 \\
Yorkshire & 30243 & $1063(3 \cdot 5)$ & 13540 \\
Trent & 77790 & $2450(3 \cdot 1)$ & 37092 \\
East Anglian & 27191 & $835(3 \cdot 1)$ & 13833 \\
North West Thames & 44404 & $2568(5 \cdot 8)$ & 24566 \\
North East Thames & 87875 & $4135(4 \cdot 7)$ & 37503 \\
South East Thames & 38935 & $1806(4 \cdot 6)$ & 17865 \\
South West Thames & 46487 & $1856(4 \cdot 0)$ & 21640 \\
Wessex & 42145 & $1566(3 \cdot 7)$ & 18542 \\
Oxford & 33357 & $1270(4 \cdot 1)$ & 16666 \\
South Western & 16603 & $466(2 \cdot 8)$ & 7891 \\
West Midlands & 227985 & $9733(4 \cdot 3)$ & 89286 \\
Mersey & 11570 & $416(3 \cdot 6)$ & 3857 \\
North Western & 119940 & $3026(2 \cdot 5)$ & 39980 \\
\hline England & 871761 & $32823(3 \cdot 8)$ & 367942 \\
Wales & 31184 & $984(3 \cdot 2)$ & 11421 \\
Scotland & 73945 & $1477(2 \cdot 0)$ & 32813 \\
Northern Ireland & 54225 & $1096(2 \cdot 0)$ & 27290
\end{tabular}

TABLE III-Regional distribution of susceptibility to rubella in pregnant women aged 15-19 and of uptake of rubella vaccine in schoolgirls aged $14^{\star}$

\begin{tabular}{|c|c|c|c|}
\hline & \multicolumn{2}{|c|}{ Pregnant women aged 15-19 } & \multirow{2}{*}{$\begin{array}{c}\% \text { Of } \\
\text { schoolgirls } \\
\text { vaccinated }\end{array}$} \\
\hline & No tested & No (\%) susceptible & \\
\hline \multicolumn{4}{|l|}{ England: } \\
\hline Northern & 9906 & $217(2 \cdot 2)$ & 91 \\
\hline Yorkshire & 5607 & $182(3 \cdot 2)$ & 88 \\
\hline Trent & 13418 & $392(2.9)$ & 90 \\
\hline East Anglian & 2630 & $101(3.8)$ & 85 \\
\hline North West Thames & 3525 & $202(5 \cdot 7)$ & 81 \\
\hline North East Thames & 8365 & $500(6 \cdot 0)$ & 80 \\
\hline South East Thames & 3960 & $209(5 \cdot 3)$ & 82 \\
\hline South West Thames & 3370 & $172(5 \cdot 1)$ & 87 \\
\hline Wessex & 3396 & $115(3.4)$ & 87 \\
\hline Oxford & 3115 & $131(4 \cdot 2)$ & 77 \\
\hline South Western & 1690 & $44(2 \cdot 6)$ & 87 \\
\hline West Midlands & 24861 & $1056(4 \cdot 2)$ & 87 \\
\hline Mersey & 1277 & $37(2 \cdot 9)$ & 91 \\
\hline North Western & 17659 & $542(3 \cdot 1)$ & 84 \\
\hline Wales & 4116 & $170(4 \cdot 1)$ & 89 \\
\hline Scotland & 9099 & $153(1 \cdot 7)$ & 84 \\
\hline Northern Ireland & 7016 & $132(1.9)$ & 85 \\
\hline
\end{tabular}

*Correlation of -0.51 of regional distribution of susceptibility to rubella with regional distribution of uptake of rubella vaccine $(p=0.035)$.

though susceptibility remained higher overall than in all other regions.

The regression line of susceptibility over time for pregnant women (fig 2) showed that the overall decrease in susceptibility in the four countries was fairly uniform. Although the rate of fall was somewhat lower in Scotland than in the other countries, Scotland had the lowest susceptibility overall.

The regional distribution of susceptibility among pregnant women aged 15-19 showed a significant correlation of $-0.51 \quad(p=0.035)$ with the regional distribution of rates of uptake of rubella vaccine in schoolgirls (table III).

\section{AGE DISTRIBUTION OF SUSCEPTIBILITY}

During the study susceptibility to rubella in pregnant women was lowest $(3 \cdot 1 \%)$ in women aged 25 29 , lower even than in women aged 15-19 (3.5\%); otherwise susceptibility generally increased with age, reaching $6.0 \%$ in those aged $40-44$ (table IV). The regions followed a similar pattern, except that in the Thames regions more than $5 \%$ of the women aged 15 19 were susceptible. Susceptibility increased during the study in women aged 40-44 and decreased in all the other age groups, most steeply in women aged 15-19 and 30-34 (fig 3).

\section{CHANGES IN METHODS OF TESTING}

Several laboratories changed their method of testing or the thresholds used during the study, but this could have been the cause of declining susceptibility in only 
TABLE IV-Distribution by age of pregnant women susceptible to rubella, 1984-6

No $(\%)$

Age (years) No tested susceptible

$\begin{array}{rrr}15-19 & 123010 & 4355(3 \cdot 5) \\ 20-24 & 326772 & 11397(3 \cdot 5)\end{array}$

25-29 $334578 \quad 10377(3 \cdot 1)$

$30-34 \quad 173639 \quad 6768(3.9)$

$\begin{array}{rrr}35-39 & 61756 & 2803(4 \cdot 5) \\ 40-44 & 11360 & 680(6 \cdot 0)\end{array}$

$40-44$

$11360 \quad 680(6 \cdot 0)$ three. These changes were not reflected in either regional or national data.

\section{Discussion}

The high proportion of the pregnant women in the United Kingdom included in this study suggests that the sample was fairly representative for all four countries. Pregnant women are the most suitable group for assessing susceptibility to rubella among women of childbearing age: they are at risk and easily reached through routine screening at antenatal clinics.

The results indicate that in all four countries of the United Kingdom over the three years of the study susceptibility to rubella decreased in pregnant women and women tested before vaccination. The proportion of susceptible women decreased most rapidly in the first two quarters of 1984 and the last two quarters of 1986. The numbers reported in the first two quarters of 1984 were, however, comparatively small as these were the first complete quarters immediately after the start of the immunisation campaign. During this period the number of reporting laboratories increased considerably. From mid-1984 to mid-1986 the susceptibility rate among pregnant women remained at $3 \cdot 5$ $3 \cdot 7 \%$, although the rate among women before vaccination fell gradually. After the second quarter of 1986 susceptibility fell considerably in both the pregnant and unvaccinated groups and especially in the group that had been tested for other reasons. There was no large natural epidemic of rubella during the study to account for this change, and if the results reported here are representative of the entire population they suggest that the decrease in susceptibility was due to vaccination.

The decrease in susceptibility over the three years of the study occurred consistently in all four countries and in all but three of the English regions. In two of these regions (West Midlands and East Anglia) the susceptibility rates were low or average, but in the third (North West Thames) they remained high. A similar decrease in susceptibility occurred in pregnant women tested by five out of eight public health laboratories and was seen in both nulliparous and parous women.

The rate of susceptibility to rubella for a region was significantly negatively correlated with the rate of uptake of rubella vaccine in schoolgirls in the region during 1983-6. A similar regional disparity in rates of uptake has been found when vaccination first began and was attributed to local awareness campaigns. ${ }^{8}$ Uptake of vaccine in independent schools was reported to be poor. ${ }^{8}$ Perhaps a larger proportion of these schools in the south east contributes to the higher susceptibility rates detected in these regions.

That the susceptibility rates were lower in women aged 25-29 probably reflects postnatal immunisation against rubella as well as the efforts of many authorities to immunise women who have not been immunised as schoolgirls. Only data on parity, which we were not able to collect, can distinguish between the two. The higher susceptibility rates in older women can probably be explained by their having missed out on rubella vaccination at school, where routine vaccination began in 1970 , and in their early childbearing years. The trends in age distribution are consistent with decreasing susceptibility to rubella and with improving vaccination rates. Despite the proportion of susceptible 15-19 year olds in the Thames regions being as high as $6.0 \%$ (compared with the national average of $3.5 \%$ ) susceptibility in this age group seemed to be decreasing at about the same rate as the national average. Nevertheless, this study suggests that the four Thames regions are not performing as well as the other regions and need to re-examine their strategy for vaccination against rubella.

As this study did not start until 1984 the results cannot show whether the rubella vaccine campaign has effected a decline in susceptibility to rubella or whether the patterns seen continued an earlier trend. Although local studies in Manchester showed that the campaign boosted requests for serotesting from women for only three months ${ }^{6}$ our findings of a steady overall decline in susceptibility to rubella in women is encouraging and suggests that there is an underlying trend due to more than a campaign.

Since routine vaccination was introduced in 1970 susceptibility in all women has steadily decreased from an initial level of $15-20 \%$. Our finding of an overall rate of $3.5 \%$ suggests that the current vaccination programme against rubella has been fairly successful but that a hard core of women of childbearing age are still susceptible. Some epidemiologists consider that it is not possible to improve greatly on this, and as the strategy for vaccination against rubella is not designed to decrease the natural circulation of rubella virus susceptible pregnant women still have a high risk of exposure to infection. To eliminate circulating rubella virus it has been decided to vaccinate against rubella as well as measles and mumps with the new triple vaccine, which is to be given between the ages of 1 and 2 .

The difficulties of monitoring the direct effects of a rubella vaccination programme on the incidence of congenital rubella include incomplete reporting, accuracy of diagnosis, ascertainment of asymptomatic congenital infections, termination of pregnancy for women who have contracted rubella, and delayed reporting. More efficient methods of surveillance are necessary. The results of this study show that the form of laboratory surveillance described in this report is feasible and representative and, together with more intensive studies, laboratory testing ${ }^{67}$ is probably the most efficient form of monitoring a rubella immunisation programme. The introduction of the combined mumps, measles, and rubella vaccine makes continued monitoring imperative.

We thank the Office of the Chief Scientist, Department of Health and Social Security, for encouragement and for funding this study and Dr C Miller for supplying data from the Manchester Public Health Laboratory.

We thank the following laboratories for their participation: Airedale General Hospital; Ashford Hospital; Ashington Hospital; Barking Hospital; Basildon Hospital; Basingstoke District General Hospital; Brighton Public Health Laboratory; Brook General Hospital; Cambridge Public Health Laboratory; Carlisle Public Health Laboratory; Castle Hill Hospital; Centra Middlesex Public Health Laboratory; Charing Cross Hospital; City Hospital Edinburgh; Coventry Public Health Laboratory; Derbyshire Royal Infirmary; Doncaster Royal Infirmary; Dorchester Public Health Laboratory; Dudley Road Hospital; Dulwich Public Health Laboratory; East Birmingham Hospital; Edgware General Hospital; Exeter Public Health Laboratory; Fife Area Laboratory; Foresterhill, Aberdeen; Guildford Public Health Laboratory; Hammersmith Hospital; Harefield Hospital; Hartlepool General Hospital; Hertfordshire and Essex General Hospital; Hospital of St Cross; Ipswich Public Health Laboratory; Kettering General Hospital; Law Hospital; Lincoln Public Health Laboratory; Liverpool Public Health Laboratory; Manchester Public Health Laboratory; Mayday Hospital; Middlesbrough Public Health Laboratory; Monklands District General Hospital; Northern Ireland Blood Transfusion Service; Newcastle Public Health Laboratory; North Ayrshire District General Hospital; North Middlesex Hospital; North Tees General Hospital; Northampton General Hospital; Nottingham Public Health Laboratory; Oxford Public Health Laboratory; Peterborough Public Health Laboratory; Poole Public Health Laboratory; : Princess Margaret Hospital, Swindon; Queen Charlotte's Hospital for Women; Queen Elizabeth Hospital, Kings Lynn; RAF Institute of Pathology and Tropical Medicine; Rotherham District General Hospital; Royal Army Medical College; Royal Free Hospital, London; Royal Gwent Hospital; Royal Hampshire County Hospital; Royal Naval Hospital, Portsmouth; Salisbury Public Health Laboratory; Sandwell District General Hospital; Sheffield Public Health Laboratory; Shrews- 
bury Public Health Laboratory; South Shields General Hospital; St Mary's Hospital, London; St Richard's Hospital, Chichester St Andrew's Hospital, London; St Thomas's Hospital, London; Stoke Mandeville Hospital; Stoke on Trent Public Health Laboratory; Sunderland District General Hospital; Swansea Public Health Laboratory; The London Hospital Medical School Tooting Public Health Laboratory; University College Hospital; Watford Public Health Laboratory; West Midland Regional Blood Transfusion Service; West Suffolk Hospital; Whipps Cross Public Health Laboratory; Whittington Hospital; Wolverhampton Public Health Laboratory; Wycombe General Hospital; York District Hospital.

1 Clarke M, Seagroatt V, Schild GC, et al. Surveys of antibodies in young adults and children. Lancet 1983;i:667.
2 Naish J. Rubella immunity in pregnant women in a north London practice. BrMed f 1984;288:1053.

3 Foster W. An opportunistic approach to rubella screening in general practice. $7 R$ Coll Gen Pract 1986;36:58-60.

4 Gilmore D, Robinson ET, Gilmour WH, et al. Effect of rubella vaccination programme in schools on rubella immunity in a general practice population BrMed f 1982;284:628-30.

5 Rowlands S, Bethel RGH. Rubella vaccination: screening all women at risk. Br Med J 1981;283:829-31.

6 Miller CL, Miller E, Sequeira PJL, $e t$ al. Effect of selective vaccination on rubella susceptibility and infection in pregnancy. $\mathrm{Br}$ Med $\mathcal{F}$ 1985;291:1398401

7 Miller CL, Miller E, Waight PA. Rubella susceptibility and the continuing risk of infection in pregnancy. $\mathrm{Br}$ Med $\mathcal{Y}$ 1987;294:1277-8.

Peckham CS, Marshall WC, Dudgeon JA, et al. Rubella vaccination of schoolgirls: factors affecting vaccine uptake. Br Med f 1977; ; :760-1.

(Accepted 16 August 1988 )

\title{
Adverse neurodevelopmental outcome of moderate neonatal hypoglycaemia
}

\author{
A Lucas, R Morley, T J Cole
}

\begin{abstract}
There has been considerable debate over whether asymptomatic neonatal hypoglycaemia results in neurological damage. In a detailed multicentre study of 661 preterm infants hypoglycaemia was found to be common. Moderate hypoglycaemia (plasma glucose concentration $<2.6 \mathrm{mmol} / \mathrm{l}$ ) occurred in 433 of the infants and in $\mathbf{1 0 4}$ was found on three to $\mathbf{3 0}$ separate days. There was considerable variation among the centres, implying differences in decisions to intervene. The number of days on which moderate hypoglycaemia occurred was strongly related to reduced mental and motor development scores at 18 months (corrected age), even after adjustment for a wide range of factors known to influence development. When hypoglycaemia was recorded on five or more separate days adjusted mental and motor developmental scores at 18 months (corrected age) were significantly reduced by 14 and 13 points respectively, and the incidence of neurodevelopmental impairment (cerebral palsy or developmental delay) was increased by a factor of 3.5 (95\% confidence interval 1.3 to 9.4 ).

These data suggest that, contrary to general belief, moderate hypoglycaemia may have serious neurodevelopmental consequences, and reappraisal of current management is urgently required.
\end{abstract}

\section{Introduction}

There is considerable debate over what should be chosen as a safe lower limit for blood glucose concentration in the neonatal period..$^{1-3}$ Glucose is the principal substrate for cerebral metabolism, and neonatal hypoglycaemia can cause damage to both neuronal and glial cells, resulting in severe handicap or death. ${ }^{4-9}$ Nevertheless, newborn infants have been regarded as fairly resistant to the pathophysiological effects of hypoglycaemia because they often remain asymptomatic at blood glucose concentrations low enough to cause severe symptoms in adults. ${ }^{8.13}$ Such asymptomatic hypoglycaemia has been claimed to have a good prognosis, ${ }^{814-18}$ suggesting that alternative metabolic substrates for the brain may be available in early life. ${ }^{3}$ To exclude the possibility that asymptomatic and moderate hypoglycaemia may cause persistent adverse effects on neurodevelopment, however, requires large numbers of subjects, and available data do not provide adequate reassurance, particularly in infants born before term, in whom hypoglycaemia is common. ${ }^{19} 20$
We examined the incidence and antecedents of low blood glucose concentrations in 661 infants of low birth weight and related the occurrence and persistence of hypoglycaemia to the neurodevelopmental outcome at 18 months after term in 543 survivors.

\section{Subjects and methods}

We studied 661 preterm infants who weighed less than $1850 \mathrm{~g}$ at birth and survived the first 48 hours of life. Their mean (SD) birth weight was 1337 (315) g, and their mean gestational age was $30.5(2.7)$ weeks; those with major congenital abnormalities were excluded. The infants, who were taking part in a large study of feeding conducted at five centres, ${ }^{21}$ were a major unselected subsample of those for whom plasma glucose monitoring had been planned. Extensive demographic, obstetric, and neonatal data were available.

Weekly plasma samples were taken from the infants and analysed for glucose. In addition, glucose concentrations were determined with reagent sticks every six hours for the first 48-72 hours. Generally, infants with a blood glucose concentration on stick testing below $1.5 \mathrm{mmol} / \mathrm{l}$ or with two or more values below $2 \cdot 0-2 \cdot 5 \mathrm{mmol} / 1$ received a blood test to determine their plasma glucose concentration. All infants requiring intensive care (most of them) were monitored daily for plasma glucose concentration, regardless of the values on stick testing. This daily sampling continued until the infant was clinically stable, of ten into the second or third week. Only data from the plasma samples are reported in this study; these samples were analysed by the glucose oxidase method. Data from 6808 samples taken on separate days are presented. The study continued until the infants were discharged or weighed $2000 \mathrm{~g}$, whichever occurred first. All infants were studied in the first week; the number still remaining in the study declined with postnatal age, falling to 428 , 260,127 , and 59 infants by the third, fifth, seventh, and ninth weeks respectively.

Early feeding practices in the centres were broadly similar. Enteral feeding started before 2 hours in large, well babies, and in ill babies and those not tolerating feeds an intravenous infusion of glucose was established immediately, progressing within 48 hours to an incremental regimen to provide total parenteral nutrition. In four of the units intravenous nutrition was accompanied by minimal enteral feeding as soon as the infant's condition was stable. In one unit (centre B), however, small, sick babies usually had elective
Lucas, MRC Dunn Nutrition Unit, Cambridge CB4 IXJ. 